\title{
THE PROFESSIONALS OF TEACHING AND BURNOUT SYNDROME: THE BASIS OF PREDICTOR VARIABLES AND THE IMBALANCE BETWEEN THE NATURE OF WORK AND THE NATURE OF THE PERSON
}

\section{REVIEW ARTICLE}

ALMEIDA, Jânie Carla Martins ${ }^{1}$

DIAS, Adailton di Lauro ${ }^{2}$

ALMEIDA, Jânie Carla Martins. DIAS, Adailton di Lauro. The professionals of teaching and Burnout Syndrome: The basis of predictor variables and the imbalance between the nature of work and the nature of the person. Revista Científica Multidisciplinar Núcleo do Conhecimento. 04 year, Ed. 11, Vol. 04, pp. 0516. November 2019. ISSN: 2448-0959, Access link in: https://www.nucleodoconhecimento.com.br/education/sweetening-professionals

\section{SUMMARY}

The theme that generates for the study refers to Burnout Syndrome and its consequences as well as its relationship with the daily life of teaching professionals. This syndrome ends up affecting the psychological side and directly interfering in the health of the worker who is directly close to people, such as students/managers/coordinators/parents of students and the demands caused by

\footnotetext{
${ }^{1}$ Master of Educational Sciences (UNIVERSIDAD GRENDAL). Specialist in Letters with emphasis on Linguistics (FASE-ES). Specialist in Portuguese Language (FACEBA). Graduated in Letters - Qualification in Portuguese Language and Portuguese Language Literatures (UNEB-BA).

2 Master's degree in Education Sciences (Grendal University). English Language Specialist (FIJ). Graduated in Letters (UNEB). Graduated in Portuguese and English from the Metropolitan University of Santos - SP.
} 
these relationships and by daily life eventually triggering psychological pressures in the work sector, consequently impairing their health and well-being. It aims, therefore, to analyze the causes of burnout syndrome in teaching professionals. As a guiding problem of the research, we sought to investigate: How does the imbalance between the nature of work and the nature of the person triggering burnout syndrome in teaching professionals occur? Therefore, we sought through a bibliographic exploratory research of a qualitative nature to discuss conceptual and causal aspects of the syndrome, and especially its relations in the area of education. This article is some considerations about the stress, characteristics and symptomatology of burnout, prevention, as well as the theme about teachers sick with burnout syndrome, addressing the physical and mental health of these professionals. The results of the research show that these professionals, due to the lack of appropriate working conditions and tiredness, end up acquiring stress that may be physical or mental, as a result of this prolonged stress situation, the professional it comes into exhaustion due to an excessive effort that makes to meet the constant requests of energy, directly compromising the quality of life of the person and, consequently, of work.

Keywords: Stress, tiredness, education professionals, burnout syndrome.

\section{INTRODUCTION}

Many investigations have been conducted regarding the process of illness of education professionals due to the continuous stress that triggers in burnout syndrome. This article, a priori, intends to analyze the causes of burnout syndrome in teaching professionals. It aims, a posteriori, to address the stress, characteristics and symptomatology of burnout, forms of prevention, as well as the theme about the physical and mental health of these professionals.

The methodology used was the bibliographic exploratory of a qualitative nature that aims to have greater knowledge about the subject. For Lakatos and Marconi (2007), research can be considered as a formal procedure with reflexive thought method that requires scientific treatment and constitutes the way to know reality or to discover partial truths. 
In this context, the research problem arises: How does the imbalance between the nature of work and the nature of the person triggering burnout syndrome in teaching professionals arise? The literature informs that teachers in the exercise of the profession in the work field, while exercising their activities have been found distinct psychosocial stressors present, some in relation to the nature of their roles at work; with respect to the environmental and/or psychosocial condition where these functions are performed.

This study is justified because burnout syndrome is the reason why many professionals suffer chronic stress by contactwith the demands of the professional environment, requiring a study on the aspects of health, social and sociological studies that can trigger the syndrome. This syndrome ends up affecting both the psychological side and directly interferes with the health of the worker who is directly close to people and suffers psychological pressures in the work sector, consequently impairing his health. Thus, it is justified the execution of this work in an attempt to seek, from literary research, to present burnout syndrome from the perspective of the educational area as well as social and psychological areas, being of great relevance to the community academic society as a whole.

\section{BURNOUT SYNDROME AND TEACHING}

There is no generic definition of burnout syndrome, there is agreement to consider that appears in the individual as a return/feedback to stress due to continuous and labor effort. It refers to a grouping of feelings that develop internally and starts to generate negative attitudes for the person, because it implies changes, problems and physiological and also psychological disorders with harmful consequences to the individual and the company in which it works. This problem triggered, most often, in health and education professionals, who deal directly with "caring for the other". In this context presented, it is considered that,

Burnout is an epidemic[..], it is an international problem, it cannot be regarded as the privilege of this or that educational or social reality, of this or that culture, this or that country. [...]Burnout[...] is also highly 
disseminated. [...]lt is present in all positions and everywhere (CODO, 1999, p. 249-250-253).

The professionals in the area of teaching who deal directly with the teaching-learning of students, that is, they are constantly under pressure for greater efficiency and demonstration of results, the burden of overloading demands, the complexity of the management of conflicts in the school field, due to the lack of appropriate working conditions and tiredness, extensive and strenuous workload, end up acquiring both physical and mental stress, in which the individual can become exhausted, due to an excessive effort which it does to respond to constant energy requests, directly affecting the quality of life and, consequently, of work.

The problems arising from the profession are combined with those caused by external sources, which are formed by what happens in the life of each being, such as the profession, lack of money, conflicts in the workplace or in the room, conditions of unhealthyness, cold, heat, losses and problems of indiscipline, fights and aggression between students.

The syndrome was attributed, extreme tiredness, wear and stress of work activities, appearing mainly in health and education professionals, who are intrinsic and repeatedly caring for the other (SMITH; SEGAL, 2018). From this perspective, Freudenberger and Richelson (2004) report that burnout stems from physical and mental exhaustion due to daily contact with other individuals in the scope of work.

It is therefore necessary to reveal actions that admit prevention, attenuation, or even stop burnout. It is noteworthy that the prevention and extinction of the syndrome in professionals are not employed by these, but it needs to consider joint action among the professionals involved, the organization, society, among others.

Work plays a central role in people's lives and is a relevant factor in the formation of identity and in their social insertion and from birth, they learn step by step how to live and what values should follow. They also go through adaptations and emotions arising from coexistence in a competitive society. 
In adulthood, the act of working becomes a must, a necessity, and often ceases to be a pleasure, since the pace is faster and advanced technology contributes to individuals seeking constant improvement and the body does not be able to respond effortlessly to the pace requested. Teaching professionals also have an accelerated pace and an excessive workload, in addition to continuously dealing with humans (students/managers).

In the 1970s, theoretical models and instruments were constructed capable of understanding the chronic feeling of discouragement, apathy, depersonalization. The first finding of scholars is that it was a problem or a syndrome that mainly affected the workers in charge of caring. Thus, Burnout was the name chosen for this syndrome; in Portuguese, it means "something like losing fire, losing energy, or burning (out) complements" (CODO; VASQUEZ-MENEZES, 1999, p. 238).

Several authors claim that the relationship that people develop with other individuals in the workplace is a source of stress. From this perspective, the term Burnout appears in the 1970s, which is an English word meaning literally "being exhausted" or "burned", and occurs more often in people who work in professions that require care for beings human rights, aid, human services (SILVA, 2000; MÜLLER, 2004; BORTOLUZZI; STOCCO, 2006; LIPP, 2008).

In this context presented, in relation to professions that can generate burnout syndrome, Silva (2000) mentions that it is those professionals who consist mainly of offering direct human services (dedication to others) and of great relevance to the User.

\subsection{STAGES OF BURNOUT - FROM STRESS TO EXHAUSTION}

What can require people's bodies, greater adaptation, creates stress, which is independent of the person himself. In this way,

External sources are made up of everything that occurs in our lives and that comes from outside our body: the profession, lack of money, fights, robberies. [...]Internal sources refer to the particular "factory" of stress. This is what exists within each individual: way of being and acting, beliefs, 
values, emotions, thoughts, anguish, joys and sorrows (BORTOLUZZI; STOCCO, 2006, p. 3).

These may be stressors, which alone do not trigger stress. For it to occur, it will depend on each individual, their life history, vulnerability, coping with situations and genetics. According to Müller (2004), the pioneering article related to stress was published in 1936 by a doctor named Hans Selye in the English journal Nature entitled "Syndrome produced by various harmful agents", in which he sought to demonstrate that stress syndrome could be studied independently of all specific changes from it.

In this article, Selye called it an "Alarm Reaction" to determine the onset of the syndrome in the individual, who first goes through an observation stage and then, through an adaptation or resistance stage that is triggered after a continued exposure to any stressor agent that may be able to provoke this reaction (MÜLLER, 2004).

For Lipp (2008), this phase focuses on a slight identification of the danger, which will prepare the body for the reaction itself. According to Müller (2004), after the phase of "Alarm Reaction" comes next, the second stage called the "Resistance Phase", in which the person's body seeks to adapt and tries to resist aggression, which can last many years.

In this context, if the body continues to be exposed to the extressor agent, in a prolonged manner, begins the third and final phase, called "Exhaustion Phase" and according to Lipp and Mallagris (1998), at this stage "the person has no more energy and his effort to adapt himself either by the disappearance of the stressor or the exhaustion of the resistance mechanisms." These phases, therefore, progressively, lead the individual to exhaustion, to stress, which will ultimately trigger bournout syndrome.

\section{THE EDUCATIONAL INSTITUTION SEEN AS A SOCIAL ORGANIZATION AND BURNOUT S YNDROME}

The educational institution, in this scenario, is seen as an organization. Among the numerous definitions for the sociological science of organizations, one of the most 
concise is to define it as the way of knowing and thinking about nature and society. Among the numerous definitions for the sociological science of organizations, one of the most concise is to define it as the way of knowing and thinking about nature and society, according to the organizational approach.

For Oliveira (2002), the Sociology of Organizations, with regard to organizations and society, has sought to institute a systematic theory of behavioral changes in society that end up directly or indirectly interfering in the performance, success and/or failure or even, in the survival of organizations. With regard to practical applicability, it takes as object of study and research, the social facts that interfere in organizations or the social facts that suffer influence from organizations themselves or their behavior. It is therefore necessary to expand this area of Sociology more and more since there is a need to study the human being in society and in the context of organizations.

The Concept of Bumout emerged to explain the process of deterioration in care and professional care in workers of organizations. It is also necessary to understand people, the main raw material with which they deal daily, not only as individuals who are, but especially as a group, since services are collectively carried out. Thus, it seeks to study how organizations work, develop strategies and achieve results, contributing to the well-being of society and community (DIAS, 2006).

\subsection{THE BASIS OF PREDICTOR VARIABLES AND THE IMBALANCE BETWEEN THE NATURE OF WORK AND THE NATURE OF THE PERSON}

In the field of sociology of organizations, from a functionalist appropriation of the concept of bureaucracy used in max weber's studies and originated in the functionalist reading made by Parsons, it is perceived that, starting from an institutionalist perspective ,

The main factor in organizational analysis and prescriptions is the degree of institutionalization/sedimentation of the ideal bureaucratic model, that the scholars of the organization pointed out the limitations of bureaucratic rationality in the practice of organizations, submitted - according to their 
nature - to a series of interferences: culture, interests, links of dependence, etc., which restricted the full realization of the bureaucratic pattern more than formal factors (MOTTA, 2004, p. 16).

From this aspect, several studies emerge that question the reliability of a rationalist abstraction, as well as studies that sought to develop a technological apparatus to better institutionalize bureaucratic rationality, efficiently. In this context, Freudenberger and Richelson (2004) mention that burnout is the result of physical, mental exhaustion, disappointment and loss of interest in the work activity that arises in professions that work in direct contact with people in service provision, such as consequence of this daily contact in your work.

According to Maslach and Jackson (2001, p. 9) "burnout is likely to occur whenever there is an imbalance between the nature of work and the nature of the person who does the job." Thus, stress and a posteriori can be triggered, a priori, burnout syndrome.

Also regarding the diagnosis, Silva (2000) relates emotional, physical and mental fatigue, with feelings of impotence and uselessness, and also, with the lack of enthusiasm for work, for life in general and also states that low self-esteem correlated with factors mentioned, has to do with states that culminate with this syndrome.

In this respect, Maslach and Jackson (2001) report that the symptoms triggered by the syndrome are nervous exhaustion and depersonalization, since exhaustion is the symptom felt by workers when they can no longer give more affective or Physically. The energy of the emotional resources of its own is exhausted. It is emotionally exhausted, due to the fact that living daily with the most diverse people. In relation to depersonalization, it defines itself as the development of negative feelings and attitudes for people in the workplace. Other professionals see them in a dehumanized way, label them negatively, and many professionals place the responsibility of their problems in these people.

The possible causes of burnout syndrome for the development of the syndrome are several, but it is necessary that there are internal and external causes that contribute 
to the formation of the process. The most likely would be, according to Codo (1999), the internal causes: 1- General provision. Without it the stressor agents (occasional) would not in themselves be able to produce the relationship with stress. It is the way we perceive the facts, depends on our ego, our psyche, the value system, which each has of himself, our heredity. 2 - Current emotional conditions. These are conditions that can turn into another internal transformation for stress. They reflect the current affective tone of the moment (or this phase of life), while personal dispositions reflect the affective profile of personality.

There are several external causes of Burnout, according to Codo (1999): little autonomy in professional performance; low wages; lack of professional perspective; conflict between work and family; problems of relationships with managers, co-workers and patients or students; scrapping of institutions; lack of incentive and financial resources of institutions.

Regarding symptoms in general, several authors report that some health professionals and also education feel a generic sensation of intense malaise, involving health problems related to anxiety, tension, nervousness, depression , anguish, insecurity, exhaustion, stress and irritability. Add to these, frustration, shortness of breath, low pressure, dizziness, labyrinthitis, sleep disorders (insomnia and sleep that is not restorative), digestive disorders, vocal cord problems, respiratory problems, allergies, forms of inadequate diet (which may imply the medium and long term, in nutritional deficiencies) (SILVA, 2000; MÜLLER, 2004; BORTOLUZZI; STOCCO, 2006; LIPP, 2008).

The authors, Maslach and Jackson (2001) as well as Delgado (2003), corroborate the statement that the symptoms arising from the syndrome soon appear and are nervous exhaustion and depersonalization. Exhaustion as his name reveals, is when the worker is extremely exhausted, tired physically and mentally, as well as affectively. In relation to depersonalization, it is defined as the appearance of desires and negative attitudes for individuals in the scope of work. 
For Lowenstein (2001), as society and the State come to understand and value the importance of providing better working conditions for health and education professionals will arise from the necessary changes, so that there is a decrease in the number of burnout cases.

\section{FINAL CONSIDERATIONS}

Burnout syndrome is characterized by physical and/or mental exhaustion, which leads to impairment of both quality of life and the quality of professional work. It is worth emphasizing that burnout is formed by several successive states that occur at a time and represent a form of adaptation to sources of stress. Thus, burnout and stress are phenomena that express their relevance in the health of the individual and the institution that works.

It is verified that, in Brazil, the problem related to quality of life at work, despite its increasing number, has been seen with disregard by the competent authorities. The solution of problems is not limited to establishing public health policies aimed at medicalization only and treatment individually, because in addition to not being a solution that solves the issue, it would only alleviate the issue.

It is necessary to establish prevention policies, because some teaching professionals have reported several symptoms that demonstrate illness, such as: malaise, tension, stress, nervousness, depression, exhaustion, frustration, shortness of breath, low or high blood pressure, dizziness, labyrinthitis, insomnia and digestive problems, and most commonly hoarseness and difficulty swallowing, respiratory problems, among others.

Thus, it is necessary to emphasize aspects related to the well-being of the individual as well as their biopsychosocial health so that it has quality of life in the work environment. Preventive and treatment measures are therefore necessary so that the syndrome does not settle down and affect the productivity and development of the individual. 
It is perceived that many professionals have the syndrome, but they do not know it, not realizing the symptoms, which arise, gradually. It is necessary to provide moments of reflection with regard to the emotional balance of professionals in the area of education, improving their interpersonal relationships and the quality of the work developed. It is therefore necessary to perform actions that prevent or mitigate or end the burnout. However, the prevention of burnout and also its eradication in professionals is not only a task for those who are with the syndrome, but need to envision a joint action between these professionals who are involved and society, between Other.

From the reflections, actions should be generated aimed at looking for options for possible changes both in the microsocial sphere in the labor sphere - including here, the organizational factors that intervene in the quality of life at work - and in the relationships among individuals.

Even though stress and burnout in education have certainly been happening for a long time among professionals, being a serious problem, the syndrome reported here is not something new; what can be new are the challenges of these professionals in identifying and declaring stress and burnout that they have been feeling. It is necessary to start a process of personal and institutional change, with constructive and participatory proposals, to manage one's own health and seek allies to start a movement that leads to the construction of healthier spaces in the work context.

Nowadays, more than ever, professionals are asked more emotionally balanced and prepared to deal with the problems of contemporary life. It is clear how important the well-being and health of the individual at work is important, since it is in this work environment that remains most of the time. The teacher, like any other individual, needs to feel valued and also special. Thus, you need both to have your needs assured and visualize in everyday life, your work being valued by those to whom it is dedicated. 


\section{REFERENCES}

BORTOLUZZI, Cibele de Lara; STOCCO, Josete Alzira Passamani. A influência do estresse no ambiente de trabalho. 2006. Disponível em http://< www.upf.br/seer/index.php/ser/article/download/1752/1162> Acesso em 24 jul. 2019.

CODO, Wanderley. Educação: carinho e trabalho. Vozes. Petrópolis: Rio de Janeiro, 1999.

CODO, Wanderley; VASQUES-MENEZES, lône. O que é burnout? Em Wanderley Codo (Org.), Educação: Carinho e trabalho (p. 237-255). Rio de Janeiro: Vozes, 1999.

DELGADO, Alvarez Cármen et al. Revisão teórica do Burnout - o desgaste em profissionais da docência. CAESURA, № 2, p. 47-65, 2003.

DIAS, Reinaldo, Sociologia das Organizações. São Paulo: Atlas, 2006.

FREUDENBERGER, Herbert J.; RICHELSON, Geraldine. Estafa: O alto custo dos empreendimentos. Rio de Janeiro: Francisco Alves, 2004.

LAKATOS, Eva Maria; MARCONI, Marina de Andrade. Técnicas de pesquisa: planejamento e execução de pesquisas, amostragens e técnicas de pesquisas, elaboração, análise e interpretação de dado. 5. ed. São Paulo: Atlas, 2007.

LIPP, Marilda Novaes. Como enfrentar o stress. São Paulo: Ícone, 2008.

LIPP, M. N.; MALAGRIS, L. N. Manejo do estresse. In: B. Rangé (org.). Psicoterapia comportamental cognitiva: pesquisa, prática, aplicações e problemas. São Paulo: Psy, 1998.

LOWENSTEIN, L. Estresse do professor levando a burnout: a sua prevenção e cura. Educação Hoje, 41(2):12-16, 2001.

MASLACH, Christina; JACKSON, Susan E. Inventário Maslach Burnout. Palo Alto: Consultoria de Imprensa do Psicólogo, 2001. 
MOTTA, F.C.P. Introdução à Organização Burocrática. São Paulo: Pioneira, 2004.

MÜLLER, Daniela Virote Kassick. A síndrome de Burnout no trabalho de assistência à saúde: estudo junto aos profissionais da equipe de enfermagem do Hospital Santa Casa de Misericórdia de Porto Alegre. Universidade Federal do Rio Grande do Sul. Escola de Engenharia. Mestrado Profissionalizante em Engenharia. Porto Alegre, 2004. p. 1-110.

OLIVEIRA, Silvio Luiz de. Sociologia das Organizações: Uma análise do Homem e das Empresas no Ambiente Competitivo. São Paulo: Pioneira, 2002.

SILVA, Flávia Pietá Paulo da. Burnout: um desafio à saúde do trabalhador. V. 2. № 1. Jun/2000. Disponível em: <http://www.seebbauru.org.br/admin/webeditor/uploads/files/burnout\%20um\%20des afio\%20a\%20saude\%20do\%20trabalhador.pdf>. Acesso em 25 jul. 2019.

SMITH, Melinda; SEGAL, Jeanne et al. Burnout: prevenção e tratamento. Helpguide.org. fev. 2018.2 Disponível em: < https://www.helpguide.org/articles/stress/burnout-prevention-andrecovery.htm?pdf=true >. Acesso em 26 jul. 2019.

Submitted: October, 2019.

Approved: November, 2019. 